\title{
Regarding all the Food Allergies
}

ISSN: 2640-9208

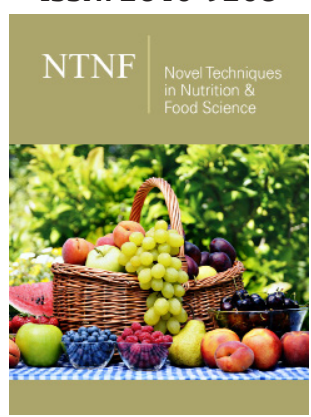

*Corresponding author: Gerry A Smith, Department of Biochemistry, Cambridge University, UK

Submission: 非 May 6, 2021

Published: 㯺 May 14, 2021

Volume 6 - Issue 1

How to cite this article: Gerry A Smith Regarding all the Food Allergies. Nov Tech Nutri Food Sci. 6(1). NTNF. 000626. 2021. DOI: 10.31031/NTNF.2021.06.000626

Copyright@ Gerry A Smith. This article is distributed under the terms of the Creative Commons Attribution 4.0 International License, which permits unrestricted use and redistribution provided that the original author and source are credited.

\section{Gerry A Smith*}

Department of Biochemistry, Cambridge University, UK

\section{Mini Review}

When I, sometime later than first published, read the article in the Telegraph newspaper describing the work of Professor Gideon Lack. His observations whilst treating patients, especially very young ones, with emollients to alleviate their skin disorders. He was extremely thorough and took careful histories to search for the causes of their afflictions, i.e., rashes and broken skin. The articles is here, https://www.telegraph.co.uk/news/worldnews/ northamerica/usa/1424292/Peanut-allergy-is-linked-to-creams-for-skin-rashes.html and also available at, https://www.sciencenews.org/blog/food-thought/unexpected-sourcespeanut-allergy. What Prof Lack found very surprisingly was confirmation of some peoples view that peanut-allergy does in fact occur without prior consumption of peanuts or derivatives thereof [1]. Being an organic chemist of considerable experience, I realized from his results that the trigger of peanut allergy in these patients had to reside in the emollients he was using. I also knew of the industrial processing used to produce these emollients from fats, i.e., triglycerides, mostly in the early days from peanut oil, hence the first cases were allergy to peanuts.

These days oil from other sources is used, e.g., soy, milk(cream), and others and not surprisingly there are allergies arising from all these foods as well. A lot of research money and time is being wasted on trying to find links to the consumption of these foodstuffs, there is absolutely no way the allergies are triggered in this way particularly with milk which all babies consume. The other main peculiarity is these food allergies are generally linked to Immunoglobulin-E (IgE) which has its own peculiarity [2,3] in that when there is consumption of the foodstuff involved when sensitised there is quite often a result of anaphylaxis. An IgE immunity is normally initiated by an invasive species with a plasma membrane containing the allergen. Allergy to things like pollen and dust etc are not normally IgE based, the instigating allergen is not membrane linked.

\section{The chemistry involved}

This is very simple and surprisingly not spotted earlier, and still not so. The emollients are mono- and di-glycerides produced from the triglycerides (fats) by base catalyzed exchange with glycerol. Any proteinaceous material present with its free nitrogen moieties will act as a far more rapid acceptor of the fatty-acyl chain from the triglyceride than the hydroxyl group of glycerol. Thus, during production of the emollient there are produced $\mathrm{N}$-fatty-acylated peptides and proteins which being detergent in nature are very difficult to remove from the detergent like product [4].

\section{Administration to humans}

Mono- and di-glycerides (glycerol with one or two fatty-acyl chains attached) are used in two main ways with regard to humans. They are either added to industrially produced foods to disperse the fats or they are administered as emollients (lotions and creams) to the skin, which is often broken the reason for their usage. The $\mathrm{N}$-fatty-acylated proteinaceous material (antigen) gets applied with the mono- and di-glyceride and inevitably via the gut or the bloodstream gets into the blood. In the blood, which contains many cell types, the fatty acylated antigen binds to cell surfaces and of course the cell it is now bound to appears as an invasive species to the host's immune system that reacts by being activated to produce immunoglobulins against the foreign proteinaceous material. In this case being cell surface 
bound a consequence is production of IgE in particular. Hence the nasty results of food allergy derived this way, which in the authors view is virtually all food allergies. Wasting time and money on finding the non-existent links to food consumption should be halted directly.

There is one other corollary That immunologists need to address. There will be an immune response directed at the combination of the introduced peptide and the host's own cell surface proteins, they are on the same cell that appears invasive. This could very well be a mechanism of developing auto immune disease. What has happened since I first published this. The answer to that question is very simple. Because there is an embargo on my work elsewhere, in cardiology, that has incorrectly stood for twenty years grossly hindering advances in that field. I have had to publish my groundbreaking work in minor journals that nobody reads. For a reason that I do not understand the same seems to apply to this work.

\section{The solution to the problem of all food allergies}

One industry is responsible, it prepares emollients and fat dispersing food additives. This industry uses impure, dirty fats, that contain proteinaceous material, to generate the mono- and diglycerides used, and these impurities get chemically incorporated in the products they make and sell. These are the initiating allergens of food sensitivity. I reiterate, eating a foodstuff, whatever it is, peanuts, milk, soy, and many others, virtually all, does not under any circumstance initiate allergy to that food. Once initiated for an allergen consumption of that allergen of course produces the effects. The worst effect is anaphylaxis, and sometimes death, this result is in particular from the way and form of the allergen when first introduced into the blood stream, vide supra.

The solution to the problem is cheap and simple. The fat source being used has to be dissolved in light petroleum spirit and this washed with acid, including a filtration step, and the acid wash carefully completely removed, and the purified triglyceride recovered by evaporation of the petroleum spirit. All proteinaceous material will be removed and hence not get into the product as an allergen [4]. There are two things needed from the governments to prevent more and more cases developing as they all have origin in the one industry. The governments have firstly to require.

a) All fats used to produce mono- and di-glycerides to be purified this way, and secondly.

b) Ban all imports of food additives and emollients from countries where the same purification regimes are not used.

\section{References}

1. Lack G, Fox D, Northstone K, Golding J (2003) Factors associated with the development of peanut allergy in childhood. N Engl J Med 348: 977-985.

2. Laffleur B, Debeaupuis O, Dalloul Z, Cogné M (2017) B cell intrinsic mechanisms constraining Ige memory. Front. Immunol 8: 1277.

3. Bell RG (1996) IgE, allergies and helminth parasites: A new perspective on an old conundrum. Immunology Cell Biology 74(4): 337-345.

4. Smith GA (2020) Food allergies: Cause and prevention. R-Infotext Citation: Clinc Res Ther Rev 01(01): 6-7. 